\title{
Clearance of Calcium across in Situ Perfused Placentas of Intrauterine Growth-Retarded Rat Fetuses ${ }^{1}$
}

\author{
M. ZULFICAR MUGHAL, RICHARDUS ROSS, AND REGINALD C. TSANG
}

The Perinatal Institute and Children's Hospital Research Foundation, The Department of Pediatrics, Division of

Neonatology, University of Cincinnati College of Medicine, Cincinnati, OH 45267-054I

\begin{abstract}
Maternofetal clearance of ${ }^{45} \mathrm{Ca}$ and ${ }^{51} \mathrm{Cr}$ EDTA (diffusional marker) were simultaneously measured across in situ perfused placentas of intrauterine growthretarded (IUGR) and control rat fetuses on d 20 of gestation. IUGR was induced by uterine artery and vein ligation on d 17 of gestation. Control fetuses and their placentas were taken from sham-operated dams. We hypothesized that calcium transfer would be impaired across placentas of IUGR fetuses. The mean body wt of IUGR fetuses was $42 \%$ lower, and the mean nose-anus length was $16 \%$ lower than those of control fetuses. The mean total calcium content of IUGR fetuses was significantly lower than that of control fetuses, but not when it was normalized to body wt. The mean maternal whole blood ionized calcium concentration was not significantly different in the two groups. The materno-fetal clearance of ${ }^{45} \mathrm{Ca}$ across IUGR placentas was significantly lower than that across control placentas $($ IUGR $=35.2 \pm 1.9 \mu \mathrm{L} / \mathrm{min} / \mathrm{g}$ placenta, mean \pm SEM; control $=93.1 \pm 12 \mu \mathrm{l} / \mathrm{min} / \mathrm{g}$ placenta, $p<0.002)$. In contrast, the maternofetal clearance of ${ }^{51} \mathrm{Cr}$-EDTA, the reference diffusional marker, was not significantly different across IUGR and control placentas. We conclude that maternofetal transfer of calcium is reduced across placentas of IUGR rat fetuses. (Pediatr Res 25:420-422, 1989)
\end{abstract}

Abbreviation

IUGR, intrauterine growth retardation

The placenta transfers large quantities of calcium to meet the demands of the rapidly mineralizing fetus. This transfer occurs mainly in the last third of pregnancy and is believed to involve active transport mechanisms as it takes place against a concentration gradient (1)

Evidence for reduced placental calcium transfer in IUGR comes from a study by Minton et al. (2), who reported a significantly reduced bone mineral content as measured by photon absorptiometry in IUGR, compared with appropriately grown infants of similar gestational age. To the best of our knowledge, there have been no direct measurements of calcium transfer across placentas of IUGR fetuses. In this study, the

Received May 13, 1988; accepted November 15, 1988

Correspondence to Dr. Zulf Mughal, MBChB, MRCP, DCH, The Department of Child Health. St. Mary's Hospital, Hathersage Road Manchester $\mathrm{M} 130 \mathrm{JH}$, England U K

Supported by NIH Grants 5P5 OHD 20748-03 and AR 36487. M.Z.M. received a travel grant from the Welicome Trust, England.

' Presented at The Society for Pediatric Research, 56th Annual Meeting, Anaheim, CA April 1987. maternofetal clearance of ${ }^{45} \mathrm{Ca}$ and ${ }^{51} \mathrm{Cr}$-EDTA were simultaneously measured across in situ perfused placentas of IUGR and control rat fetuses, ${ }^{51} \mathrm{Cr}$-EDTA being used to provide a measure of maternofetal transfer by diffusion. IUGR was induced by uterine artery and vein ligation (3), and sham-operated dams served as controls. We hypothesized that the maternofetal transfer of calcium would be impaired across placentas of IUGR fetuses.

\section{MATERIALS AND METHODS}

Materials. All chemicals were reagent grade, and were purchased from Sigma Chemical Co. (St. Louis, MO). Radioisotopes and Aquosol II liquid scintillation cocktail were purchased from New England Nuclear (Boston, MA).

Animals and surgical procedure. Time-mated Sprague-Dawley rats were purchased from Zivic Millar Lab Inc. (Allison Park, PA) on d 14 of gestation. They were housed in individual cages and allowed free access to water and Purina Rat Chow (RalstonPurina Co., St. Louis, MO). On d 17 of gestation (term $=22 \mathrm{~d}$ ), a low midline laparotomy was performed under methoxyflurane anesthesia (Metofane, Pitman-Moore Inc., Washington Crossing, $\mathrm{NJ}$ ). In rats with five or more conceptuses in each uterine horn, uterine vessels (artery and vein) to both the horns were ligated at the level of the cervix using 4-0 silk ligatures. The abdominal incisions were closed with 3-0 silk sutures, and the animals were allowed to recover. Sham-operated animals had the same vessels exposed but not ligated and the same duration of anesthesia as the experimental group. The total duration of surgery was approximately $20 \mathrm{~min}$ in each animal.

Placental perfusion. Details of the in situ placental perfusion technique, which is modified from the original description of Stulc et al. (4) has been described elsewhere (5). A schematic diagram of the perfusion system is shown in Figure 1. Briefly, on $\mathrm{d} 20$ of gestation, the dams were anesthetized with $110 \mathrm{mg} /$ $\mathrm{kg}$ sodium thiobutabarbitol injected intraperitoneally. The maternal rectal temperature was maintained at $37^{\circ} \mathrm{C}$ throughout the experiment. A maternal jugular vein was cannulated for injection of tracers, and a carotid artery for blood pressure monitoring and blood sampling. After laparotomy and hysterotomy, one of the fetuses was delivered. Modified Krebs-Ringer solution containing $\mathrm{NaCl} 118 \mathrm{mM}, \mathrm{KCl} 4.7 \mathrm{mM}, \mathrm{CaCl}_{2} 1.25 \mathrm{mM}, \mathrm{KH}_{2} \mathrm{PO}_{4}$ $1.18 \mathrm{mM}, \mathrm{MgSO}_{4} 1.18 \mathrm{mM}, \mathrm{NaHCO}_{3} 25 \mathrm{mM}$, glucose $11 \mathrm{mM}$, and $3.5 \%$ dextran $(40000 \mathrm{~mol} \mathrm{wt})$, was gassed continuously with a mixture of $95 \% \mathrm{O}_{2}$ and $5 \% \mathrm{CO}_{2}$ at $37^{\circ} \mathrm{C}$ and pumped by a peristaltic pump (Hake-Buchler, Saddle Brook, NJ) into the fetal circulation of the placenta, via a cannula in the umbilical artery. The perfusion rate varied from 0.28 to $0.39 \mathrm{~mL} / \mathrm{min}$ between experiments, but remained constant during any individual experiment. After a single pass through the placenta, perfusate effluent was collected from a cannula in the umbilical vein. 


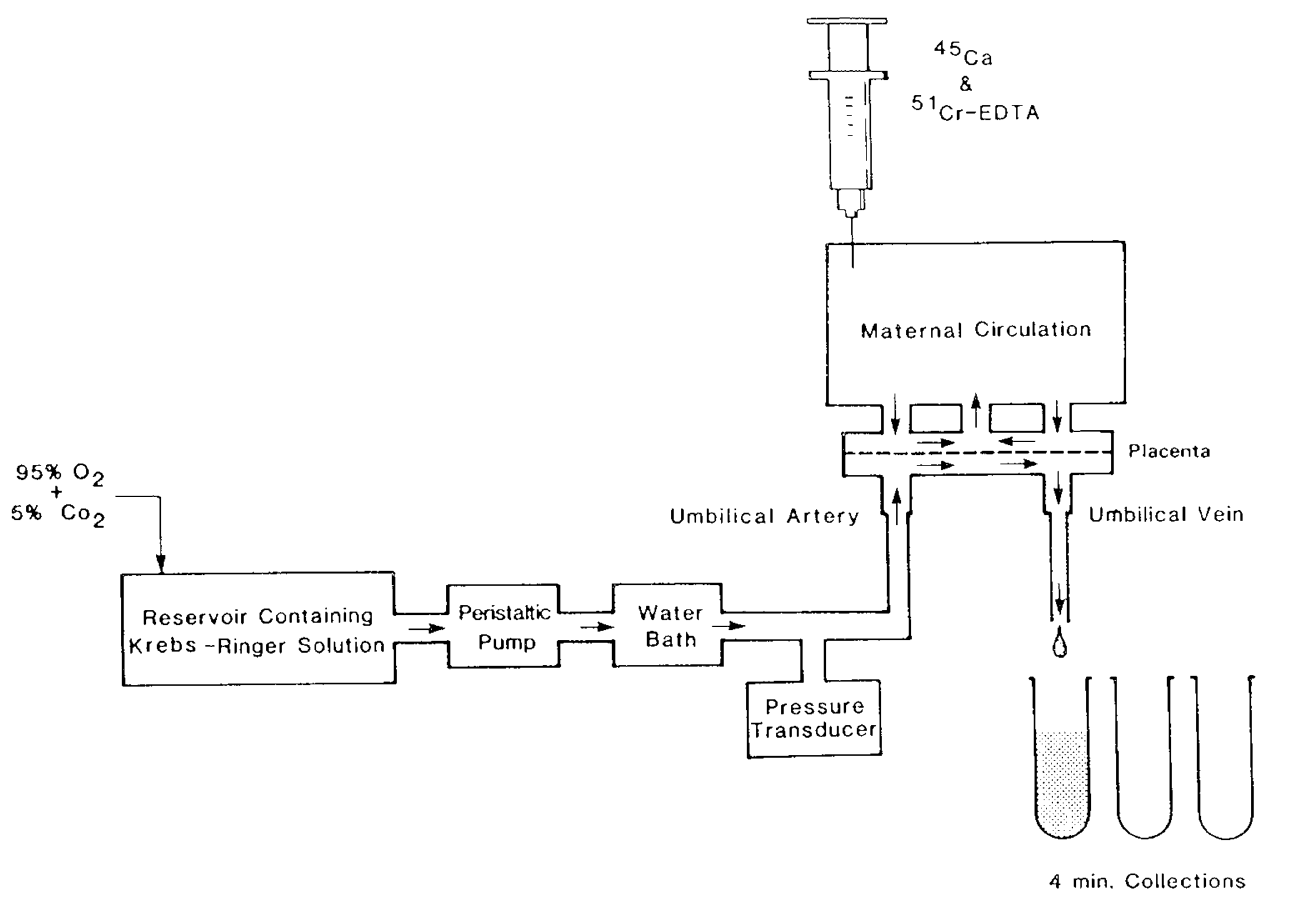

Fig. 1. Schematic diagram of in situ perfused rat placenta.

Maternal arterial pressure and perfusion pressure were measured using precalibrated Gould-Statham pressure transducers (Gould Inc., Cleveland, $\mathrm{OH}$ ) and recorded continuously on a chart recorder.

Each fetus whose placenta was perfused was removed after the vessels had been cannulated, blotted with tissue paper and weighed to an accuracy of $0.1 \mathrm{mg}$ using a Mettler H5 1AR balance (Mettler Corp., Cleveland, $\mathrm{OH}$ ) and its nose-anus length was measured to an accuracy of $1 \mathrm{~mm}$ using Vernier calipers. At the end of the experiment, the perfused placenta was detached from the uterine wall, and its wet wt measured to an accuracy of 0.001 $\mathrm{mg}$, after fetal membranes and the umbilical cord had been trimmed off. Each fetus in which the placenta had been perfused was ashed at $600^{\circ} \mathrm{C}$ for $12 \mathrm{~h}$ in a muffle furnace, and its ash as dissolved in $1-\mathrm{N} \mathrm{HCl}$ and brought to the appropriate vol with deionized water. The total fetal calcium content was measured using a Varian AA-1475 atomic absorption spectrophotometer (Varian Techtron Ltd., Mulgrave, Australia). Maternal whole blood ionized calcium concentration, corrected to $\mathrm{pH}$ 7.4, was measured using a Radiometer ICA 1 analyzer (Radiometer, Copenhagen) at the start and end of each experiment.

Selection of placentas for perfusion. Uterine artery ligation results in the death and partial resorption of a variable number of fetuses near the cervical pole of the uterus. The surviving fetuses exhibit progressive decrease in body wt from the ovarian to the cervical pole of the uterus (3). In this study, fetuses in each horn were numbered sequentially so that fetus number 1 was nearest to the cervix and the last number nearest to the ovary. In experimental animals, the placenta of the smallest live fetus, which was the placenta of fetus number 3,4 , or 5 was perfused. Placentas of the correspondingly numbered fetuses in control animals were studied.

Placental transfer. After an equilibriation period of 5 to 10 min, $10 \mu \mathrm{Ci}$ of ${ }^{45} \mathrm{Ca}$ as $\mathrm{CaCl}_{2}(27 \mathrm{mCi} / \mathrm{mg})$ and $40 \mu \mathrm{Ci}$ of ${ }^{51} \mathrm{Cr}$ EDTA $(500-800 \mathrm{mCi} / \mathrm{mg})$ each in 0.1 to $0.2 \mathrm{~mL} 0.9 \% \mathrm{NaCl}$ were injected at time 0 as a bolus into the maternal circulation via a cannula in the jugular vein. The use of high sp act of ${ }^{51} \mathrm{Cr}$ EDTA as a diffusional marker does not result in a measurable change in the maternal ionized $\mathrm{Ca}$ concentration. At approximately 3,13 , and $25 \mathrm{~min}, 0.5-\mathrm{mL}$ heparinized maternal blood samples were drawn from a cannula in the carotid artery for radioisotope counting. After allowing $5 \mathrm{~min}$ for the injected ${ }^{45} \mathrm{Ca}$ to come into equilibrium with the intraplacental pool of ${ }^{45} \mathrm{Ca}$, three 4-min collections of perfusate effluent were taken in each experiment. The rationale for the $5 \mathrm{~min}$ delay comes from the observations of Stulc et al. (4) that the rat placenta has a small intraplacental pool of ${ }^{45} \mathrm{Ca}$, and from our preliminary experiments in which we found that the calculated maternofetal placental clearance of ${ }^{45} \mathrm{Ca}$ and ${ }^{51} \mathrm{Cr}$-EDTA had reached a maximum value by this time. ${ }^{45} \mathrm{Ca}$ activity $(\mathrm{cpm})$ in aliquots of plasma and of perfusate effluent were counted for $10 \mathrm{~min}$ in Aquosol II scintillation cocktail using a Packard Tri-carb $460 \mathrm{CD}$ liquid scintillation counter (Packard Instruments Co, Downers Grove, IL). ${ }^{51} \mathrm{Cr}$ activity (cpm) in aliquots of plasma and of perfusate effluent were counted for $10 \mathrm{~min}$ in a Packard 5330 auto-gamma spectrometer (Packard Instuments Co). Appropriate corrections were made for background counts and cross-contamination of $\beta$ counts with $\gamma$ counts.

Exclusion criteria. A successful perfusion was one in which the perfused placenta was uniformly blanched (due to removal of fetal blood) and placental perfusate effluent recovery was 95$100 \%$ of the inflow vol. There were more exclusions in the IUGR group than in the control group, mainly due to nonuniform blanching of perfused placentas in the former group. All exclusions were made before counting of plasma and perfusate samples.

Calculations. The steady state clearance of ${ }^{45} \mathrm{Ca}$ from maternal plasma to each perfusate sample $(\mu \mathrm{L} / \mathrm{min})$ was defined as:

$$
\text { maternofetal clearance of }{ }^{45} \mathrm{Ca}=\frac{\mathrm{P} \times \mathrm{F}}{\mathrm{m}} \times 1000
$$

where $\mathrm{P}$ is the ${ }^{45} \mathrm{Ca}$ concentration $(\mathrm{cpm} / \mathrm{mL})$ in perfusate effluent samples, $\mathrm{M}$ is the ${ }^{45} \mathrm{Ca}$ concentration $(\mathrm{cpm} / \mathrm{mL}$ ) in the maternal plasma at the midpoint of each 4-min collection period, and $\mathrm{F}$ is the rate at which the perfusate was pumped through the placenta $(\mathrm{mL} / \mathrm{min})$. To normalize for differences in placental size in different experiments, the clearance was related to the wet wt of the perfused placentas $(\mu \mathrm{L} / \mathrm{min} / \mathrm{g}$ placenta). The maternofetal clearance of ${ }^{51} \mathrm{Cr}$-EDTA was calculated in an analogous manner. Mean $\mathrm{mf}$ clearance values for each isotope for each experiment was obtained from three successive perfusate samples. 
Table 1. Mean ( \pm SEM) fetal wt, nose-anus length, placental $w t$, and total calcium content of fetuses of perfused placentas

\begin{tabular}{lccc}
\hline & $\begin{array}{c}\text { IUGR } \\
(n=6)\end{array}$ & $\begin{array}{c}\text { Control } \\
(n=6)\end{array}$ & $p$ \\
\hline Fctal wt $(\mathrm{g})$ & $2.33 \pm 1.84$ & $4.06 \pm 0.20$ & $<0.001$ \\
Nose-anus length $(\mathrm{cm})$ & $3.25 \pm 0.08$ & $3.87 \pm 0.07$ & $<0.001$ \\
Placental wt $(\mathrm{g})$ & $0.355 \pm 0.05$ & $0.416 \pm 0.03$ & $<0.05$ \\
Total fetal calcium (mg) & $5.4 \pm 0.4$ & $8.5 \pm 0.3$ & $<0.001$ \\
Total fetal calcium/fetal & $2.33 \pm 0.1$ & $2.13 \pm 0.1$ & $\mathrm{NS}$ \\
$\quad$ wt $(\mathrm{mg} / \mathrm{g})$ & & & \\
\hline
\end{tabular}

Statistics. The data are presented as mean \pm SEM, and the difference between means in each group were analyzed using Student's $t$ test for unpaired samples.

\section{RESULTS}

The data on fetal wt and nose-anus length, placental wt, and total calcium content of fetuses whose placentas were perfused are summarized in Table 1.

The mean maternofetal clearance of ${ }^{45} \mathrm{Ca}$ across placentas of IUGR fetuses was $35.2 \pm 1.9 \mu \mathrm{L} / \mathrm{min} / \mathrm{g}$ placenta, which was significantly $(p<0.002)$ lower than the mean value of $93.1 \pm$ $12 \mu \mathrm{L} / \mathrm{min} / \mathrm{g}$ placenta across placentas of control fetuses. In contrast, the maternofetal clearance of ${ }^{51} \mathrm{Cr}$-EDTA across the IUGR placentas $(5.7 \pm 1.0 \mu \mathrm{L} / \mathrm{min} / \mathrm{g}$ placenta) was not significantly different from that across control placentas $(4.7 \pm 0.5 \mu \mathrm{L} /$ $\mathrm{min} / \mathrm{g}$ placenta). The mean maternal whole blood ionized calcium concentrations in IUGR and the controls was not significantly different at $1.34 \pm 0.06$, and $1.24 \pm 0.05 \mathrm{mmol} / \mathrm{L}$ respectively.

The mean maternal blood pressure during placental perfusion in the IUGR group $(97.6 \pm 8.2 \mathrm{~mm} \mathrm{Hg})$ was not significantly different from that in the control group $(83.6 \pm 7.9 \mathrm{~mm} \mathrm{Hg})$. The mean perfusion pressure in the IUGR group was $16.6 \pm 1.7$ $\mathrm{mm} \mathrm{Hg}$, which was not significantly different from that in the IUGR group, $14.1 \pm 3.3 \mathrm{~mm} \mathrm{Hg}$.

\section{DISCUSSION}

In the classical Wigglesworth model (3), fetal growth retardation was experimentally induced in one uterine horn by uterine artery and vein ligation, and fetuses in the contralateral horn served as controls. We used a protocol suggested by Kollee $e t$ al. (6), in which IUGR fetuses were taken from dams with bilateral uterine vessel ligation and controls from sham-operated animals, because the latter investigators reported increased variability in wt and aberrant carbohydrate metabolism in control fetuses from the contralateral horn of the Wigglesworth model. Maternofetal ${ }^{45} \mathrm{Ca}$ clearance across the in situ perfused rat placenta has been previously demonstrated to be only slightly lower than the in vivo clearance across placentas of both anesthetised and nonanesthetised intact animals (4). The results of the present perfusion study indicate that the maternofetal clearance of ${ }^{45} \mathrm{Ca}$ was strikingly reduced across placentas of IUGR fetuses; by contrast, clearance of ${ }^{51} \mathrm{Cr}$-EDTA was unchanged. In the absence of a significant difference in maternal whole blood ionized calcium concentration between the two groups, a fall in ${ }^{45} \mathrm{Ca}$ clearance across IUGR placentas is consistent with a fall in maternofetal calcium flux in the latter.

The mechanism by which ligation of uterine blood vessels results in reduced placental calcium transfer is not known. However, it is unlikely to be due to decreased saturation of the maternofetal calcium transporting system because of the unchanged maternal whole blood ionized calcium concentrations. A decreased placental "porosity" or surface areas is also unlikely because of the unchanged maternofetal ${ }^{51} \mathrm{Cr}$-EDTA clearance.
Flow limitation in the supply of calcium at the maternal face of the placenta is also unlikely (7) but has not been rigorously excluded, especially after uterine artery ligation.

In mammals, it is widely believed that placental calcium transfer in the maternofetal direction involves active transfer process, as it takes place against a concentration gradient, both in vivo (1) and across the in situ perfused placenta $(4,8,9)$. The mechanisms involved in placental calcium transfer are not fully known. From studies involving uptake of ${ }^{45} \mathrm{Ca}$ by vesicles prepared from microvilli and microsomal membranes of the human placenta (10), it has been suggested that hydrolysis of ATP may provide a source of energy for the placental "calcium transporting pump." For example, the ovine uteroplacental unit consumes approximately $45 \%$ of uterine oxygen uptake and approximately $72 \%$ of the glucose delivered to it (11). Although part of the glucose extracted by the fetoplacental unit is converted to lactate in this species, the bulk of the glucose and oxygen is likely to be utilized for placental metabolic activity. Thus, chronic reduction in utroplacental blood flow might result in depletion of the necessary energy supply for active transport across IUGR placentas.

Factors regulating placental calcium transfer are not known, but they are likely to be hormonal as the placenta has no nerve supply. In experimentally growth-retarded lambs, fetal serum concentration of such hormones as insulin, thyroxin and prolactin are decreased compared with control fetuses (12). In the sheep, there is indirect evidence that 1,25 dihydroxyvitamin $D$, the hormonal form of vitamin $D$, produced by the fetus may regulate placental calcium transfer (13). Thus, impaired production of hormones regulating placental transfer in utero may speculatively be another possible mechanism for impaired calcium transfer across placentas of IUGR fetuses.

Acknowledgments. The authors thank Emily Hall and Gemma Wiesman for technical support, and Dr. B. L. Specker and Dr. V. Hillier for statistical analysis. We also thank Professor R. D. H. Boyd, Dr. F. Mimouni and Dr. A. Behre for their constructive criticisms of the manuscript.

\section{REFERENCES}

1. Schaumberger CW, Pitkin RM 1978 Maternal-perinatal calcium relationships. Obstet Gynecol 53:74-76

2. Minton SD, Steichen JJ, Tsang RC 1983 Decreased bone mineral content in small-for-gestational age infants compared with appropriate for gestational age infants: normal 25 -hydroxyvitamin $D$ and decreasing parathyroid hormone. Pediatrics 71:383-388

3. Wigglesworth J 1964 Experimental growth retardation in the foetal rat. J Pathol Bacteriol 88:1-13

4. Stulc J, Stulcova B 1986 Transport of calcium by the placenta of the rat. J Physiol 371:1-16

5. Mughal MZ, Robinson NR, Sibley CP 1986 Perfusion of the rat placenta in situ. J Physiol (Lond) 377:5P

6. Kollee L, Mannens L, Trijbels J, Veerkamp J, Jassen A, Haard-Hustings H 1979 Experimental intrauterine growth retardation in the rat: evaluation of the Wigglesworth model. Early Hum Dev 3:295-300

7. Canning J, Boyd RDH 1984 Mineral and water exchange between mother and fetus. In: Beard RW, Nathanielsz PW (eds) Fetal Physiology and Medicine. Marcel Decker Inc., New York, pp 481-590

8. Twardock AR, Austin MK 1970 Calcium transfer in perfused guinea pig placenta. Am J Physiol 219:540-545

9. Weatherly AP, Ross R, Pickard DW, Care AD 1983 The transfer of calcium during perfusion of the placenta in intact and thyroparathyroidectomised shcep. Placenta 4:271-278

10. Whitsett JA, Tsang RC 1980 Calcium uptake and binding by membrane fractions of human placenta: ATP-dependent calcium accumulation. Pediatr Res 14:769-771

11. Meschia G, Battaglia FC, Hay WW, Sparks JW 1980 Utilization of substrates by the ovine placenta in vivo. Fed Proc 39:245-249

12. Robinson JS, Falconar J, Owens JA 1985 Intrauterine growth retardation: clinical and experimental. Acta Paediatr Scand (suppl) 319:135-142

13. Ross R 1983 Vitamin D metabolism in the pregnant large animal. In: Holick MF, Gray TK Anasat CS (eds) Perinatal Calcium and Phosphrous Metabolism. Elsevier Science Publishers, Amsterdam, pp 35-56 